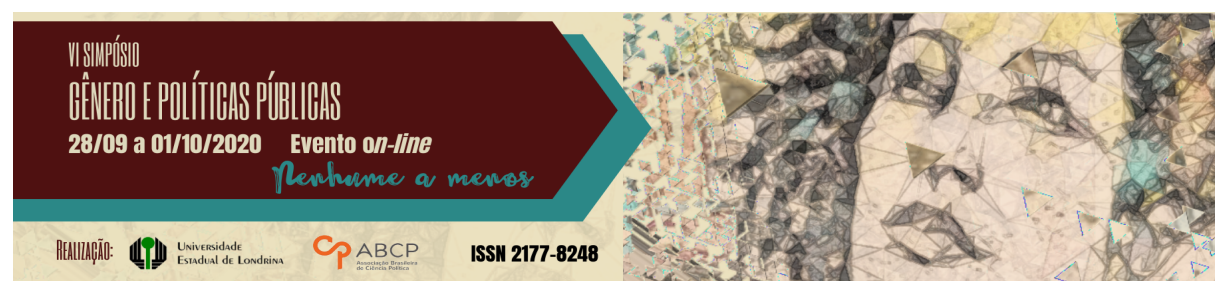

\title{
A difusão de políticas internacionais para o empoderamento econômico das mulheres no Brasil durante o governo Dilma Rousseff (2011-2016)
}

\author{
Sabrina Moura de Oliveira'; Silvana Schimanski ${ }^{2}$
}

\section{Resumo}

O presente trabalho investiga se as diretrizes internacionais da ONU para o empoderamento econômico das mulheres, alinham-se com as políticas públicas com recorte de gênero implementadas no governo Dilma Rousseff, a partir do conceito de difusão internacional de políticas públicas (DOLOWITZ, MARSH, 2000; ZAEI, 2014; BERNARDO, 2016; FARIA, 2018). Por meio da abordagem qualitativa, foi criado um quadro analítico-interpretativo, a fim de identificar, na primeira seção, os conceitos e instrumentos internacionais que poderiam representar fontes de difusão de políticas internacionais. E, na segunda, as leis pró gênero promulgadas entre 2011 e 2016, bem como a norma específica sobre empoderamento econômico das mulheres e compará-la com as resoluções internacionais acerca do tema. A análise considera que instrumentos internacionais difundiram, via emulação (DOLOWITZ, MARSH, 2000), objetivos políticos para a lei adotada no Brasil, em 2013, a qual visa a promoção do empoderamento econômico de mulheres.

Palavras-chave: difusão internacional de políticas, gênero, empoderamento econômico, Dilma Rousseff.

\footnotetext{
1 Bacharel em Relações Internacionais pela Universidade Federal de Pelotas. E-mail sssabrinam@hotmail.com

2 Doutora em Relações Internacionais pela Universidade de Brasília, Mestra em Relações Internacionais pela Universidade Federal do Rio Grande do Sul, Bacharel em Administração com Habilitação em Comércio Exterior pela Universidade do Vale do Itajaí. E-mail sischima@hotmail.com

GT 18 - Políticas públicas de gênero no Brasil do século XXI: avanços e desafios
} 


\title{
The diffusion of international policies to the economic empowerment of women during Dilma Roussef (2011-2016)
}

\begin{abstract}
This paper analyzes whether the UN international guidelines for the economic empowerment of women are in line with the public policies with a gender perspective implemented in the Dilma Rousseff government, based on the concept of international diffusion of public policies (DOLOWITZ, MARSH, 2000; ZAEI, 2014; BERNARDO, 2016; FARIA, 2018). Through the qualitative approach, an analytical-interpretative framework was created, in order to identify, in the first section, the international concepts and instruments that could represent sources of diffusion of international policies. And, in the second, the pro-gender laws enacted between 2011 and 2016, as well as the specific rule on women's economic empowerment and compare it with international resolutions on the topic. The analysis considers that international instruments disseminated, through emulation (DOLOWITZ, MARSH, 2000), political objectives for the law adopted in Brazil, in 2013, which aims to promote the economic empowerment of women.
\end{abstract}

Keywords: internacional diffusion of policies, gender, empowerment, Dilma Roussef.

\section{Introdução}

O relatório do Programa das Nações Unidas para o Desenvolvimento (PNUD) para o Brasil destaca que enquanto a renda nacional bruta estimada feminina é de \$10.073, a masculina é aproximadamente $74.4 \%$ maior (PNUD, 2018). Além disso, estudo da Organização para Cooperação e Desenvolvimento Econômico (OCDE) aponta que, no Brasil, as mulheres estão mais propensas a desempenhar trabalho informal e possuem vínculos mais fracos com o mercado de trabalho (GURRÌA, 2018). No país, a diferença entre taxas de emprego de homens e mulheres é de 20\% (GURRÌA, 2018).

É no contexto dessas diferenças que cabe questionar-se em que medida as diretrizes internacionais (ONU, 1979; 1994; 1995) que promovem o empoderamento econômico das mulheres alinham-se com 
alguma das 12 leis instituídas no governo Dilma Rousseff (2011-2016) para a promoção da igualdade de gênero. A referida organização internacional merece destaque, pois promove a agenda internacional para diversos temas, tanto por meios vinculantes (Tratados, Convenções) quanto não vinculantes (diretrizes, metas, agendas, etc).

Por meio da abordagem qualitativa, baseada no conceito de difusão de políticas internacionais, foram consultadas fontes primárias (documentos da ONU e Leis brasileiras) e secundárias (relatórios e publicações diversas). Na primeira parte do trabalho discutem-se os conceitos norteadores e instrumentos internacionais que poderiam representar fonte de difusão de políticas internacionais. Na segunda, são apresentadas as leis pró gênero promulgadas entre 2011 e 2016, bem como identifica-se a norma referente ao desenvolvimento socioeconômico das mulheres e compara-a com as resoluções internacionais acerca do tema. Por fim, a análise leva a concluir que no período em foco, as diretrizes da ONU influenciaram, por meio da emulação - utilizando o conceito de difusão de políticas de Dolowitz e Marsh (2000) - a construção de leis a favor do empoderamento econômico feminino no Brasil.

\section{Difusão de Políticas Públicas Internacionais}

Autores que trabalham com o conceito de difusão de políticas públicas, defendem que sua formulação ultrapassa as fronteiras nacionais (DOLOWITZ; MARSH, 2000; ZAEI, 2014; BERNARDO, 2016; FARIA, 2018). Atualmente, os formuladores devem considerar o que ocorre nos diálogos no ambiente internacional, ao invés de apenas considerar aspectos locais. Nesse contexto, os representantes dos Estados têm sido bastante criativos, aproveitando informações obtidas em suas interações em diversos ambientes ${ }^{3}$, inclusive das Organizações

3 “Na literatura específica, é comum que se reconheça a existência de três tipos principais de organizações internacionais (OIs), quais sejam: as organizações intergovernamentais, as organizações não governamentais internacionais (ONGs internacionais) e as empresas multinacionais. Parece claro que todas elas têm o potencial de impactar as 
Internacionais Governamentais (DOLOWITZ; MARSH, 2000).

Assim, entende-se que a difusão de política pública ocorre quando as políticas de um governo ou período específico, são transferidas - integralmente ou com adaptações - para arranjos administrativos ou instituições de outro período ou lugar (DOLOWITZ; MARSH, 1996 apud BERNARDO, 2016). Nesse contexto, a interação promovida no ambiente das instituições internacionais passou a exercer mais influência e poder (DOLOWITZ; MARSH, 2000).

As organizações internacionais podem desempenhar um papel de transferência voluntária - a partir de disseminação de ideias, programas, instituições em nível internacional - e coercitiva, seja pela característica dos instrumentos vinculantes negociados ou através de políticas e condições de empréstimo (DOLOWITZ; MARSH, 1996 apud BERNARDO, 2016). São cada vez mais difundidas as estratégias de assistência técnica e financeira internacional para a implementação doméstica de determinadas agendas.

De uma forma ou de outra, pode-se afirmar que a interação dos representantes estatais, no âmbito das Organizações Internacionais, é propícia para difusão de políticas públicas, a qual pode se dar de diversas formas, bem como em diferentes graus. Dolowitz e Marsh (2000) formularam um modelo para a análise, o qual destaca os diferentes graus dessa transferência possíveis o qual segue descrito no Quadro 1.

políticas públicas do Estado nacional, ainda que de maneiras distintas e com propósitos diversos" (FARIA, 2018, p. 21). 
Quadro 1 - Modelo de transferência de políticas públicas

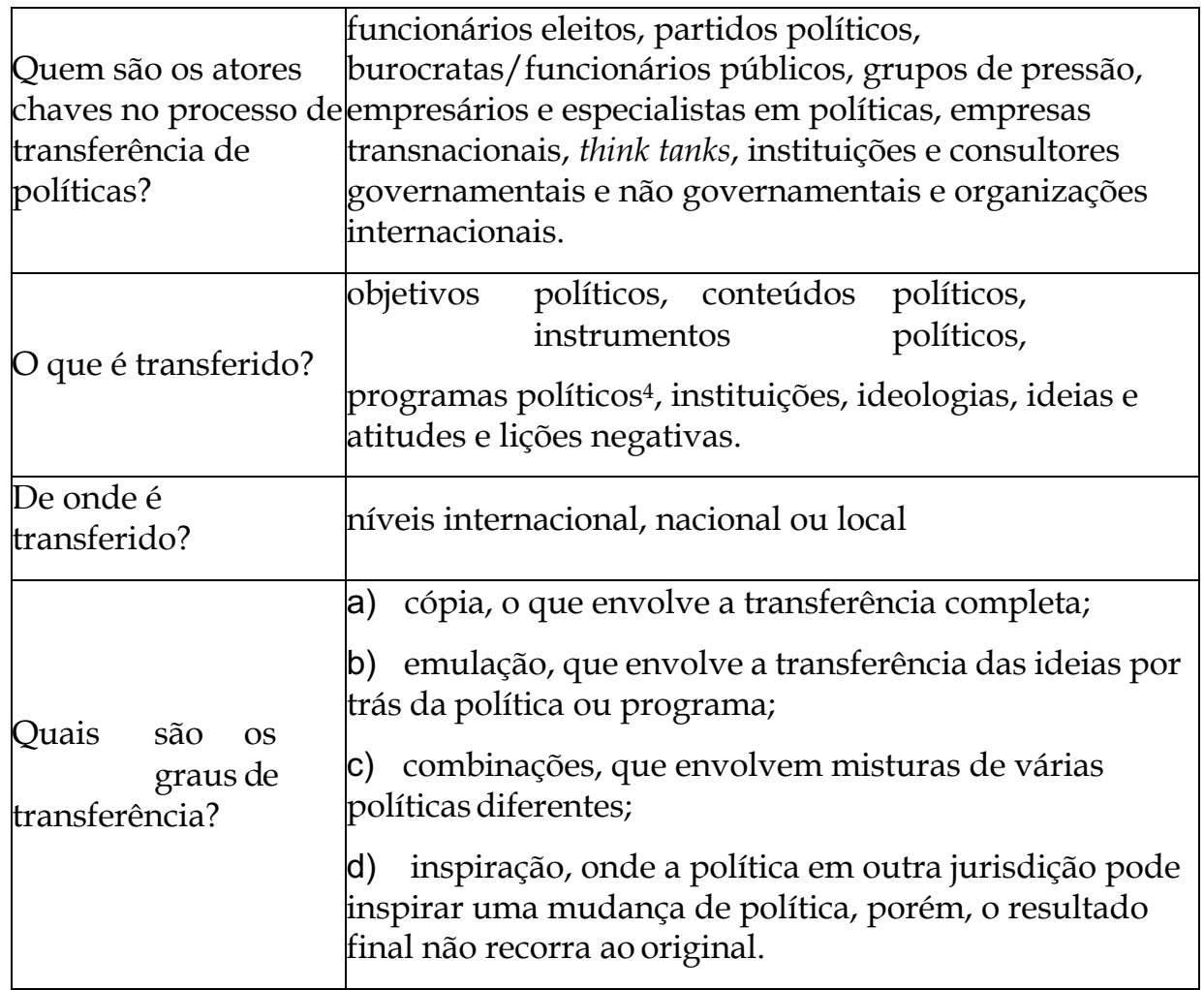

Fonte: Adaptado de Dolowiz e Mash (2000).

Apesar de diversos autores afirmarem que, no processo de difusão de políticas públicas, existem importadores e exportadores e que esse papel raramente muda (ROBERTSON 1991; ROBERTSON e WALTMAN 1992; ROSE 1993 apud DOLOWITZ; MARSH, 2000), para Dolowitz e Marsh (2000), essas posições não devem ser engessadas, uma vez que a construção das políticas não é linear e um país pode, por 
exemplo, importar modelos de políticas econômicas e exportar políticas sociais e de saúde.

Embora a discussão sobre gênero em diversas organizações internacionais não seja novidade (ONU, 1979), pode ser considerada mais recente a atenção dada ao empoderamento econômico das mulheres, no âmbito da ONU (UN Women, 2013), como será visto adiante. $\mathrm{O}$ empoderamento econômico das mulheres vai além dos direitos humanos e contribui para os estudos sobre Economia Política Feminista, área a qual, apesar da sua importância, permanece negligenciada ou incompreendida (BEDFORD; RAI, 2013).

É buscando contribuir com esses debates, que a importação brasileira de políticas presentes nos instrumentos internacionais, visando a promoção do empoderamento econômico de mulheres, merece ser discutida. Na sequência, serão apresentados os principais instrumentos internacionais sobre a garantia do direito das mulheres e promoção da igualdade de gênero.

\section{Empoderamento econômico feminino}

Atualmente a ONU define o empoderamento econômico feminino como "a capacidade das mulheres de ter garantidos empregos decentes, acumular ativos e influenciar instituições e políticas públicas que influenciam no crescimento e desenvolvimento" (UN Women, 2013, tradução minha). Para isso, a ONU instrui os países a realizarem reformas a fim de garantir direitos igualitários aos recursos econômicos, a valorização do trabalho doméstico e de cuidado não remunerados, políticas de proteção social, entre outras (ONU Mulheres, 2015, n.p).

Diversas ações iniciadas no âmbito da comunidade internacional - seja mudanças normativas ou outros mecanismos - podem estimular alterações e moldar parâmetros dentro dos quais os temas são discutidos no âmbito doméstico dos Estados. Entretanto, esse processo nem sempre é fácil e automático. Por isso, Hunt e Samman (2016) 
argumentam que um conjunto de Leis e políticas são importantes para garantir às mulheres oportunidades igualitárias sobre o tema, já que, ambientes restritivos podem limitar significativamente as escolhas econômicas das mulheres.

Instrumentos da ONU para o empoderamento econômico das mulheres

No âmbito internacional, a pauta de gênero foi incluída na agenda ainda na década de 1970, com a Convenção para a Eliminação de Todas as Formas de Discriminação contra a Mulher (CEDAW,ONU, 1979), na qual propõe-se "promover os direitos da mulher na busca da igualdade de gênero e reprimir quaisquer discriminações contra a mulher nos Estados-parte" (PIMENTEL, 2013, p.2). O documento, que possui força de lei entre os signatários, é considerado o "parâmetro mínimo das ações estatais na promoção dos direitos humanos das mulheres e na repressão às suas violações" (PIMENTEL, 2013, p.3). Na Convenção - incorporada integralmente pelo Brasil em 2002 - é importante destacar os artigos 3, 13 e 14, que deixam marca relevante para o empoderamento econômico das mulheres ao responsabilizar os Estados a tomar medidas inclusive de caráter legislativo para assegurar o pleno desenvolvimento das mulheres; eliminar a discriminação da mulher nas esferas da vida social e econômica; enfatizar a necessidade de incluir a mulher rural nos debates sobre agricultura familiar incluindo os trabalhos não remunerados - a fim de assegurar a aplicação dos dispositivos da Convenção à essa parcela da população (BRASIL, 2002).

Porém, é a partir da década de 1990, que a pauta passa a aparecer explicitamente nos documentos e resoluções. A ONU Mulheres atua desde 20105, amparada por uma série de instrumentos contendo

5 Dando continuidade a um trabalho da década anterior realizado pelo Fundo de Desenvolvimento das Nações Unidas para a Mulher (UNIFEM). 
compromissos assumidos pelos Estados-Membros, relacionados aos direitos das mulheres, bem como seu empoderamento econômico (ONU Mulheres, 2017).

Embora se reconheça a contribuição de outros instrumentos internacionais nesse debate (HUNT, SARWAR, 2017; SILVA, 2018), este trabalho foca na listagem sob o escopo da ONU Mulheres, cujo propósito, em última análise, seria provocar mudanças nas políticas públicas dos países. Assim, além da Convenção para a Eliminação de Todas as Formas de Discriminação contra a Mulher (ONU, 1979), os seguintes instrumentos são relevantes 6 :

A) Declaração e Programa de Ação de Viena (1993): que enfatiza a necessidade de adoção de medidas globais em favor das mulheres, a importância da participação das mulheres no processo de um desenvolvimento sustentável e equitativo (ONU, 1993, p.16).

B) Relatório da Conferência Internacional sobre população e Desenvolvimento - a plataforma de Cairo (1994): que trata, entre outras coisas, sobre a saúde reprodutiva como um direito humano (ONU, 1994).

C) Convenção Interamericana para Prevenir, Punir e Erradicar a Violência contra a Mulher (Convenção Belém do Pará, 1994): que reconhece a eliminação da violência contra a mulher como indispensável para a garantia do desenvolvimento e estabelece como dever do Estado firmar procedimentos jurídicos justos e eficazes para julgar esses casos (ONU, 1994).

D) Declaração e Plataforma de Ação de Pequim (1995): em Conferências anteriores (Nairobi, 1985; Copenhague, 1980; e México, 1975), foram identificadas 12 áreas prioritárias, que envolviam, entre outros pontos, as mulheres em situação de pobreza, a desigualdade de gênero no acesso à educação, saúde e aos recursos econômicos; e a violência contra a mulher. Esta Declaração, portanto, delineou um 
conjunto de objetivos estratégicos para sanar as deficiências nas 12 áreas prioritárias (VIOTTI, 2013).

Como este trabalho tem por objetivo focar nos instrumentos direcionados ao empoderamento econômico feminino, foram elencados para a análise do item 3.1 aqueles que, em seu conteúdo, possuíam menção à eliminação de discriminação de gênero, garantia de pleno acesso a recursos econômicos, progresso e capacidade de tomada de decisão às mulheres, quais sejam: os Arts. 3, 13 e 14 da Convenção para a Eliminação de Todas as Formas de Discriminação contra a Mulher (ONU, 1979); parágrafos 3.18, 4.4, 5.9 e 6.4 da Plataforma do Cairo (ONU, 1994) e parágrafos da Plataforma de Pequim (ONU, 1995).

\section{Leis com recorte de gênero no Governo Dilma Roussef (2011-2016)}

Ao analisar a produção político-legislativa, em prol da equidade de gênero, no âmbito federal entre os anos 2011-2016, Barreto, Cedaro e Miguel (2017, p. 7-9), identificaram a promugação de 12 leis para a promoção da redução de desigualdades entre os gêneros (Quadro 3), as quais os autores classificaram em quatro categorias, sendo elas: a) Leis que contribuem [...] para uma gradativa construção de história e memória das desigualdades de gênero (1 a 3); b) Dimensão de equipagem institucional e orçamentária (4 e 5); c) Enfrentamento às violências contra a mulher (6 a 8); d) efetivo empoderamento feminino (9 a 12) .

Esse conjunto de leis representa o reconhecimento da história e da luta das mulheres negras contra o racismo, machismo e violência de classe; a promoção - como política pública - da autonomia da mulher e enfrentamento à violência de gênero (BRASIL, 2015); a institucionalização do feminicídio como circunstância qualificadora do homicídio (e o avanço em reconhecer que mulheres morrem todos os dias, pelo fato de serem mulheres) e, por fim, a garantia de independência financeira da mulher - que, como consequência, reduz o percentual de vítimas de violência doméstica que não denunciam, uma 
vez que $34 \%$ das vítimas não o fazem por depender financeiramente do parceiro (DATASENADO, 2013).

Quadro 3 - Leis para a promoção da redução de desigualdades entre os gêneros aprovadas no governo Dilma Rousseff.

\begin{tabular}{|l|l|l|l|}
\hline & \multicolumn{1}{|c|}{ Lei } & $\begin{array}{l}\text { Publicada } \\
\text { no DOU de }\end{array}$ & \multicolumn{1}{|c|}{ Descrição } \\
\hline 1 & $\begin{array}{l}\text { Lei 12.987, } \\
\text { de 2.6.2014 }\end{array}$ & 3.6 .2014 & $\begin{array}{l}\text { Dispõe sobre a criação do Dia Nacional de } \\
\text { Tereza de Benguela e da Mulher Negra }\end{array}$ \\
\hline $\mathbf{2}$ & $\begin{array}{l}13.086, \text { de } \\
8.1 .2015\end{array}$ & 9.1 .2015 & $\begin{array}{l}\text { Institui, no Calendário Oficial do Governo } \\
\text { Federal, o Dia da Conquista do Voto Feminino } \\
\text { no Brasil }\end{array}$ \\
\hline $\mathbf{3}$ & $\begin{array}{l}13.272, \text { de } \\
15.4 .2016\end{array}$ & 18.4 .2016 & $\begin{array}{l}\text { Institui o ano de 2016 como o Ano do } \\
\text { Empoderamento da Mulher na Política e no } \\
\text { Esporte. }\end{array}$ \\
\hline $\mathbf{4}$ & $\begin{array}{l}12.865, \text { de } \\
9.10 .2013\end{array}$ & 10.10 .2013 & $\begin{array}{l}\text { [...]; autoriza a União a contratar o Banco do } \\
\text { Brasil S.A. ou suas subsidiárias para atuar na } \\
\text { gestão de recursos, obras e serviços de } \\
\text { engenharia relacionados ao desenvolvimento de } \\
\text { projetos, modernização, ampliação, construção } \\
\text { ou reforma da rede integrada eespecializada } \\
\text { para atendimento da mulher em situação de } \\
\text { violência; }\end{array}$ \\
\hline $\mathbf{5}$ & $\begin{array}{l}13.224, \text { de } \\
23.12 .2015\end{array}$ & 24.12 .2015 & $\begin{array}{l}\text { Abre ao Orçamento Fiscal da União, em favor da } \\
\text { Presidência da República, da Secretaria de } \\
\text { Políticas para as Mulheres e da Controladoria- } \\
\text { Geral da União, crédito suplementar no valor de } \\
\text { R\$ 44.355.000,00, para reforço de dotações } \\
\text { constantes da Lei Orçamentária vigente. }\end{array}$ \\
\hline
\end{tabular}




\begin{tabular}{|l|l|l|l|}
\hline 6 & $\begin{array}{l}\text { 13.025, de } \\
3.9 .2014\end{array}$ & 4.9 .2014 & $\begin{array}{l}\text { Altera o art. 1o da Lei no 10.714, de 13 de agosto } \\
\text { de 2003, que autoriza o Poder Executivo a } \\
\text { disponibilizar, em âmbito nacional, número } \\
\text { telefônico destinado a atender denúncias de } \\
\text { violência contra a mulher. }\end{array}$ \\
\hline 7 & $\begin{array}{l}\text { 13.104, de } \\
9.3 .2015\end{array}$ & 10.3 .2015 & $\begin{array}{l}\text { Altera o art. 121 do Decreto-Lei no 2.848, de 7 de } \\
\text { dezembro de 1940 - Código Penal, para prever o } \\
\text { feminicídio como circunstância qualificadora do } \\
\text { crime de homicídio, e o art. 1o da Lei no 8.072, } \\
\text { de 25 de julho de 1990, para incluir o } \\
\text { feminicídio no rol dos crimes hediondos }\end{array}$ \\
\hline $\mathbf{8}$ & $\begin{array}{l}\text { 13.239, de } \\
30.12 .2015\end{array}$ & 31.12 .2015 & $\begin{array}{l}\text { Dispõe sobre a oferta e a realização, no âmbito } \\
\text { do Sistema Único de Saúde - SUS, de cirurgia } \\
\text { plástica reparadora de sequelas de lesões } \\
\text { causadas por atos de violência contra a mulher. }\end{array}$ \\
\hline $\mathbf{9}$ & $\begin{array}{l}\text { 12.605, de } \\
3.4 .2012\end{array}$ & 4.4 .2012 & $\begin{array}{l}\text { Determina o emprego obrigatório da flexão de } \\
\text { gênero para nomear profissão ou grau em } \\
\text { diplomas. }\end{array}$ \\
\hline $\mathbf{1 0}$ & $\begin{array}{l}\text { 13.014, de } \\
21.7 .2014\end{array}$ & 22.7 .2014 & $\begin{array}{l}\text { Altera as Leis no 8.742, de 7 de dezembro de } \\
\text { 1993, e no 12.512, de 14 de outubro de 2011, para } \\
\text { determinar que os benefícios monetários nelas } \\
\text { previstos sejam pagos preferencialmente à } \\
\text { mulher responsável pela unidade familiar }\end{array}$ \\
\hline $\mathbf{1 1}$ & $\begin{array}{l}\text { 13.112, de } \\
30.3 .2015\end{array}$ & 31.3 .2015 & $\begin{array}{l}\text { Altera os itens 1o e 2o do art. 52 da Lei no 6.015, } \\
\text { de 31 de dezembro de 1973, para permitir à } \\
\text { mulher, em igualdade de condiçôes, proceder ao } \\
\text { registro de nascimento do filho. }\end{array}$ \\
\hline $\begin{array}{l}\text { 13.165, de } \\
29.9 .2015\end{array}$ & 29.9 .2015 & $\begin{array}{l}\text { Altera as Leis nos 9.504, de 30 de setembro de } \\
\text { 1997, 9.096, de 19 de setembro de 1995, e 4.737, } \\
\text { de 15 de julho de 1965 - Código Eleitoral, para } \\
\text { reduzir os custos das campanhas eleitorais, } \\
\text { simplificar a administração dos Partidos } \\
\text { Políticos e incentivar a participação feminina. }\end{array}$ \\
\hline
\end{tabular}

Fonte: BARRETO; CEDARO; MIGUEL, 2017.

Na sequência, serão analisados os aspectos da Lei 13.014, de 21 de julho de 2014, por seu papel de promotora do empoderamento econômico das mulheres. A mesma promoveu alteração das "leis 
número 8.742, de 7 de dezembro de 19937, e número 12.512, de 14 de outubro de $2011^{8}$, para determinar que os benefícios monetários nelas previstos sejam pagos preferencialmente à mulher responsável pela unidade familiar" (BARRETO; CEDARO; MIGUEL, 2017, p.9). Entre estes benefícios destacam-se:

a) "benefícios em virtude de nascimento, morte, situações de vulnerabilidade temporária e de calamidade pública" (art. 22); "transferências de renda, trabalho social com famílias e oferta de serviços socioeducativos para crianças e adolescentes que se encontrem em situação de trabalho" (art.24-C); e "investimentos econômico-sociais nos grupos populares" objetivando a garantia de meios, de "capacidade produtiva e de gestão para melhoria das condições gerais de subsistência e elevação do padrão da qualidade de vida" (art 25).

b) o recebimento dos recursos financeiros do Programa de Apoio à Conservação Ambiental, bem como do Programa de Fomento às Atividades Produtivas Rurais preferencialmente pela mulher responsável para a unidade familiar, quando cabível (art. 5, § 3; art. 13, $\S 5$, respectivamente).

\section{Empoderamento econômico das brasileiras}

No Brasil, a questão de gênero ganha espaço com a preparação para a Conferência Internacional para População e Desenvolvimento (Cairo, 1994) mas é importante notar que os documentos da Década das Conferências $^{9} \quad$ (LINDGREN-ALVES, 2018) referentes ao empoderamento econômico feminino foram promulgados apenas a

\footnotetext{
7 Lei Orgânica de Assistência Social (BRASIL, 1993), referente a "política de Seguridade Social não contributiva, que provê os mínimos sociais, realizada através de um conjunto integrado de ações de iniciativa pública e da sociedade, para garantir o atendimento às necessidades básicas" (BRASIL, 1993).

8 Lei que institui o Programa de Apoio à Conservação Ambiental e o Programa de Fomento às Atividades Produtivas Rurais.

9 Período de 1992 a 1996 no qual os direitos humanos foram centralidade na política internacional (LINDGREN-ALVES, 2018).
} 
partir de 2002. Ou seja, institucionalmente, é um debate recente no país.

Visando identificar se é possível afirmar que houve difusão de políticas públicas internacionais da ONU, para as políticas de empoderamento econômico das mulheres do governo Dilma, bem como seu grau de transferência, foram resgatados trechos pertinentes dos instrumentos internacionais com este recorte.

Em relação as recomendações consonantes ao primeiro artigo da lei número 13.014, de 21 de julho de 2014, cujo texto informa o repasse para a mulher da casa - quando possível - do recebimento de benefícios e serviços socioeducativos para crianças e adolescentes em situação de trabalho infantil, entre outros, ou seja, que diz respeito à políticas públicas realizadas para a redução da pobreza e do trabalho infantil. Merece destaque a CEDAW (ONU, 1979) cujos artigos 3 e 13 prevêem a responsabilização do Estado na garantia do pleno desenvolvimento e progresso da mulher; a Plataforma de Cairo (ONU, 1994), que reconhece a erradicação da discriminação da mulher em todos os âmbitos de sua vida como um pré requisito para a erradicação a pobreza e que cabe ao Estado eliminar todos os tipos de violência de gênero; e a Plataforma de Pequim (ONU, 1995), que prevê a promoção da independência financeira das mulheres por meio do acesso igualitário a recursos econômicos e oportunidades, além de também responsabilizar o Estado na proposição de políticas de ajuste estrutural e incorporação de uma perspectiva de gênero em todas as políticas e programas.

Nesses documentos, é notória a construção progressiva de um ambiente internacional propício à apresentação de parâmetros mínimos que não só garantam o desenvolvimento adequado às mulheres mas também a proteção das crianças e adolescentes que delas dependem. É consenso entre os documentos analisados, o papel do Estado na promoção de independência financeira e de ampliação do poder de decisão das mulheres em todos os âmbitos da vida.

No Brasil, aproximadamente 15 milhões de mulheres residem em áreas rurais, representando $47 \%$ da população rural, dessas 15 
milhões de mulheres, $30 \%$ não possui rendimento e 30\% recebe entre meio e um salário mínimo. Em contrapartida, elas são responsáveis por, aproximadamente, $80 \%$ dos alimentos produzidos, principalmente os de subsistência (MAPA, 2019). Além disso, a Organização das Nações Unidas para Alimentação e Agricultura (FAO, 2018) constatou que 27\% da população rural brasileira estava na condição de pobreza multidimensional, em 2012.

No tocante as recomendações que vão ao encontro do Art. 2 da lei em questão, que trata da concessão de recursos financeiros dos programas de conservação ambiental e fomento às atividades produtivas rurais, preferencialmente, para a mulher responsável pela unidade familiar, são relevantes os artigos 13 e 14 da CEDAW (ONU, 1979) que especificam o direito de obter empréstimos bancários e outras formas de crédito financeiro como medida para a erradicação da discriminação de gênero e ressalta a obrigação do Estado em considerar os problemas específicos da mulher rural, tomando medidas para assegurar a aplicação dos dispositivos da Convenção a elas também. Bem como, os pontos 3.18, 4.4, 5.9 e 6.4 da Plataforma de Cairo (ONU, 1994) que defende uma especial atenção às políticas de desenvolvimento e minoração da pobreza, especialmente nas zonas ruais e a melhoria da situação da mulher. E, por fim, a Plataforma de Pequim (ONU, 1995) que incentiva a atuação de instituições públicas e privadas na concessão de empréstimos e incentivos as mulheres urbanas e rurais, bem como ressalta o papel do Estado em assegurar o potencial de geração de renda e o acesso a recursos produtivos pelas mulheres rurais.

Todos os documentos elencados têm como consenso a urgência de se começar a implementar a abordagem de gênero nos relatórios produzidos, bem como levar esses documentos em consideração na elaboração de políticas públicas. Concordam, também, quanto a iminente necessidade de elaboração de políticas públicas voltadas para a erradicação da pobreza no campo.

Portanto, a lei brasileira mais específica e alinhada à temática do empoderamento econômico feminino (Lei 13.014 de 2014), não pode ser categorizada como uma cópia completa de nenhum dos instrumentos 
internacionais analisados ${ }^{10}$. Conforme sugerem Dolowiz e Mash (2000), acerca dos graus de transferência, é possível afirmar que a transferência aconteceu gradativamente, de forma voluntária, no grau de emulação. Ou seja, houve a internalização, no Brasil, das ideias por trás das políticas ou programas relativos ao empoderamento econômico das mulheres. Assim, o debate no seio das organizações internacionais difundiu do nível internacional, a passos lentos, para o nacional.

\section{Considerações Finais}

Nas últimas décadas, as Organizações Internacionais se multiplicaram e diversificaram em termos de áreas de atuação e formas de operação, o que resultou numa maior influência na produção de políticas domésticas, tanto como arena de troca de experiências entre Estados, quanto como agentes de transferência voluntária ou coercitiva através de suas resoluções (DOLOWITZ; MARSH, 1996 apud BERNARDO, 2016).

Na Economia Política Feminista, a análise das relações de gênero e estratégias de empoderamento é considerada um dos viéses de estudo (BEDFORD; RAI, 2013). O empoderamento econômico feminino diz respeito à reivindicação da autonomia na tomada de decisões e acesso igualitário a recursos econômicos (GOLLA et al, 2011). Na arena internacional, esse debate inicia em 1979, com a Convenção para a Eliminação de Todas as Formas de Discriminação contra a Mulher (ONU, 1979) e intensifica-se na década de 1990.

Dilma Rousseff foi eleita em 2010 com uma proposta de governo que prometia ampliar as iniciativas do governo anterior, no sentido de promover oportunidades às minorias sociais. Já em 2014, a questão de gênero teve especial atenção em seu programa, defendendo a violência zero e o empoderamento e autonomia da mulher (ROUSSEF, 2010;2014).

10Tal confirmação poderia ser possível com os autores da proposta legislativa, o que não foi possível durante a execução deste trabalho. 
Tendo isso em vista, o presente artigo propôs analisar o processo de elaboração de políticas públicas no Brasil, sob a ótica da difusão de políticas. Em que medida as políticas visando o empoderamento econômico das mulheres, são resultado direto de obrigações ou de políticas e diretrizes negociados nas arenas internacionais?

Para responder esse questionamento, foram elencadas as ações do governo brasileiro no período Dilma Roussef (2011-2016) em relação à políticas públicas voltadas para o empoderamento econômico das mulheres bem como as decisões dos fóruns internacionais que fossem favoráveis ao tema entre 1979 e 2015 a fim de investigar os pontos de convergência entre as propostas dos instrumentos internacionais e as políticas domésticas adotadas no referido governo.

Dentre as leis 12 pró-gênero promulgadas nesse período (BARRETO; CEDARO; MIGUEL, 2017), uma dizia respeito a independencia financeira das mulheres: a Lei de número 13.014, de 21 de julho de 2014. E nas diretrizes internacionais da ONU analisadas, três documentos apresentaram recomendações nesse sentido: a Convenção para a Eliminação de Todas as Formas de Discriminação contra a Mulher (ONU,1979), a Plataforma de Cairo (ONU, 1994) e a Plataforma de Pequim (ONU, 1995).

Analisando as contribuições desses foruns internacionais na promoção de debates de temas relevantes para o estabelecimento de direitos igualitários entre os gêneros no país, por meio da promulgação de diversos documentos de diretrizes internacionais da ONU, é possível reconhecer a influência das normas internacionais nas normas brasileiras.

Os documentos supracitados apresentam recomendações de objetivos - pleno desenvolvimento e progresso da mulher, eliminação da discriminação social e econômica, independência financeira, entre outros. Não recomendam uma política específica ou a forma com que esses objetivos serão alcançados, transferindo, portanto, um objetivo político que, em algum momento, se transformará em uma política 
pública. Tendo isso em vista, inferiu-se que houve a difusão por meio da emulação - conceito desenvolvido por Dolowitz e Marsh (2000) - de objetivos políticos a partir de fóruns internacionais para o âmbito doméstico. O processo de emulação ocorre quando há a transferência de ideias que resultaram em políticas ou programas (DOLOWITZ; MARSH, 2000).

É importante pontuar que esse processo não é instantâneo: um acordo, convenção ou declaração internacional pode levar - e normalmente leva - anos para ser reconhecido nacionalmente e, depois disso, ainda mais tempo para ser efetivamente implementado. Tratando-se de assuntos envolvem interesses diversos e consideráveis avanços sociais, como as questões de gênero, essa dinâmica pode se estender ainda mais como, por exemplo, no caso da Convenção para a Eliminação de todas as Formas de Discriminação Contra as Mulheres que é de 1979 mas só foi reconhecida integralmente com força de lei no Brasil em 2002, 23 anos da sua publicação.

\section{Referências}

BARRETO, Tácia Silva de Sá; CEDARO, José Juliano; MIGUEL, Vinicius Valentin Raduan. Equidade de gênero e as recentes inovações políticolegislativas: uma breve análise sobre a produção no âmbito federal entre os anos de 2011-2016. 2017. Disponível em: https://jus.com.br/artigos/54981/equidade-de-genero-e-asrecentes- inovacoes-politico-legislativas>. Acesso em: 04 set. 2019.

BEDFORD, Kate; RAI, Shirin M..Feminists Theorize International Political Economy. 2013. Disponível em: https://www.eir.info/2013/03/30/feminists-theorize-international-politicaleconomy/. Acesso em: 20 nov. 2019.

BERNARDO, Glaucia Julião. Organizações internacionais como agentes de transferência e difusão de políticas públicas. Conjuntura Global, [s.1.], v. 5, n. 2, p. 233- 252, 22 nov. 2016.

BRASIL. Decreto $n^{\circ} 4377$, de 13 de setembro de 2002. Promulga a Convenção sobre a Eliminação de Todas as Formas de Discriminação 
contra a Mulher, de 1979, e revoga o Decreto n 89.460, de 20 de março de 1984. Brasília, 2002. Disponível em: http://www.planalto.gov.br/ccivil_03/decreto/2002/D4377.htm/. Acesso em: 20 nov. 2019.

BRASIL. Decreto $n^{0} 4.316$, de 30 julho de 2002. Promulga o Protocolo Facultativo à Convenção sobre a Eliminação de Todas as Formas de Discriminação contra a Mulher. Brasília, 2002. Disponível em: http://www.planalto.gov.br/ccivil_03/decreto/2002/D4316.htm/> . Acesso em: 20 nov. 2019.

BRASIL. Lei $n^{\circ}$ 12.512, de 14 de outubro de 2011. Institui o Programa de Apoio à Conservação Ambiental e o Programa de Fomento às Atividades Produtivas Rurais; altera as Leis n 10.696, de 2 de julho de 2003, 10.836, de 9 de janeiro de 2004, e 11.326, de 24 de julho de 2006. Brasília, 2011. Disponível em: http://www.planalto.gov.br/ccivil_03/_Ato20112014/2011/Lei/L12512.htm/. Acesso em: 20 nov. 2019.

BRASIL. Lei $n^{\circ} 13.014$, de 21 de julho de 2014. Altera as Leis $n^{\circ} 8.742$, de 7 de dezembro de 1993, e $\mathrm{n}^{\mathrm{o}} 12.512$, de 14 de outubro de 2011, para determinar que os benefícios monetários nelas previstos sejam pagos preferencialmente à mulher responsável pela unidade familiar. Brasília, 2014. Disponível em: http://www.planalto.gov.br/ccivil_03/_Ato20112014/2014/Lei/L13014.htm/. Acesso em: 20 nov. 2019.

BRASIL. Lei $n^{0}$ 13.224, de 23 de dezembro de 2015. Abre ao Orçamento Fiscal da União, em favor da Presidência da República, da Secretaria de Políticas para as Mulheres e da Controladoria-Geral da União, crédito suplementar no valor de $\mathrm{R} \$ 44.355 .000,00$, para reforço de dotações constantes da Lei Orçamentária vigente. Brasília, 2015. Disponível em: http://www.planalto.gov.br/CCIVIL_03/_Ato20152018/2015/Lei/L13224.htm/. Acesso em: 20 nov. 2019.

BRASIL. Lei $n^{\circ}$ 8.742, de 7 de dezembro de 1993. Dispõe sobre a organização da Assistência Social e dá outras providências, e legislação correlata. Brasília, 1993. Disponível em: http:/ / bd.camara.gov.br/bd/handle/bdcamara/15641/. Acesso em: 20 nov. 2019. 
DATASENADO (Comp.). Pesquisa Violência Doméstica e Familiar contra a Mulher. 2013. Dados compilados pelo Instituto Patrícia Galvão. Disponível em: https://dossies.agenciapatriciagalvao.org.br/dadose-fontes/pesquisa/pesquisa- violencia-domestica-e-familiar-contraa-mulher-datasenado-2013/. Acesso em: 08 out. 2019.

DOLOWITZ, David P.; MARSH, David. Learning from Abroad: The Role of Policy Transfer in Contemporary Policy-Making. Governance, [s.l.], v. 13, n. 1, p.5-23, jan. 2000.

FARIA, Carlos Aurélio Pimenta de. Políticas públicas e relações internacionais. Brasília: Escola Nacional de Administração Pública, 2018.

GOLLA, Anne Marie et al. Understanding and Measuring Women's Economic Empowerment: Definition, Framework and Indicators. S.i: International Center For Research On Women (icrw), 2011. 12 p.

HUNT, Abigail; SAMMAN, Emma. Women' s economic empowerment: Navigating enablers and constraints. Londres: Overseas Development Institute, 2016. 40 p.

HUNT, Abigail; SARWAR, Moizza Binat. Women's Economic Empowerment at International Level. Londres: Citizens' Rights And Constitutional Affairs European Parliament, 2017.36 p.

LINDGREN-ALVES, José Augusto. A década das conferências: 1990-1999. 2. ed. Brasília: Fundação Alexandre de Gusmão, 2018.

MAPA (Comp.). Mulheres rurais se destacam em diferentes atividades $e$ buscam acesso a direitos. 2019. Disponível em: http:/ / www.agricultura.gov.br/noticias/mulheres-rurais-sedestacam-em-diferentes-atividades-e-buscam-visibilidade-para-seusdireitos. Acesso em: 17 out. 2019.

OCDE. Guidelines for gender equality and women's empowerment in development cooperation. Paris: OCDE, 1999.

ONU MULHERES. Paridade de gênero: Por um planeta 50-50 em 2030, um passo decisivo pela igualdade de gênero. 2016. Disponível em: http:/ / www.onumulheres.org.br/planeta5050-2030/ paridade/. Acesso em: 11 out. 2019. 
ONU MULHERES. Sobre a ONU Mulheres. 2017. Disponível em: http:// www.onumulheres.org.br/onu-mulheres/sobre-a-onumulheres/. Acesso em: 26 nov. 2019.

ONU MULHERES. Uma Vitória Leva à Outra. 2016. Disponível em: http://www.onumulheres.org.br/umavitorialevaaoutra/. Acesso em: 20 nov. 2019.

ONU MULHERES. Empoderamento Econômico. 2015. Disponível em: http:// www.onumulheres.org.br/areas-tematicas/empoderamentoeconomico/. Acesso em: 20 nov. 2019.

ORGANIZAÇÃO DAS NAÇÕES UNIDAS - ONU. Convenção Sobre A Eliminação de Todas As Formas de Discriminação Contra A Mulher. Nova York, 1979.

ORGANIZAÇÃO DAS NAÇÕES UNIDAS - ONU. Declaração das Nações Unidas sobre os Direitos dos Povos Indígenas. Nova York, 2007

ORGANIZAÇÃO DAS NAÇÕES UNIDAS - ONU. Declaração e Plano de Ação de Durban. Durban, 2001.

ORGANIZAÇÃO DAS NAÇÕES UNIDAS - ONU. Declaração $e$ Plataforma de Ação da IV Conferência Mundial Sobre a Mulher. Pequim, 1995.

ORGANIZAÇÃO DAS NAÇÕES UNIDAS - ONU. Declaração $e$ Programa de Ação de Viena. Viena, 1993.

ORGANIZAÇÃO DAS NAÇÕES UNIDAS - ONU. Em dia internacional, UNFPA reforça importância de lutar contra machismo e racismo. 2019. Disponível em: https://nacoesunidas.org/em-dia-internacionalunfpa-reforca-importancia-de-lutar- contra-machismo-e-racismo/. Acesso em: 20 nov. 2019.

ORGANIZAÇÃO DAS NAÇÕES UNIDAS - ONU. Protocolo facultativo à Convenção sobre a Eliminação de Todas as Formas de Discriminação Contra a Mulher. 1999. Disponível em: http:/ / www.onumulheres.org.br/wpcontent/uploads/2013/03/convencao_cedaw.pdf/. Acesso em: 28 nov. 2019. 
ORGANIZAÇÃO DAS NAÇÕES UNIDAS - ONU. Relatório da Conferência Internacional sobre população e Desenvolvimento - Plataforma de Cairo, 1994. Cairo, 1994.

ORGANIZAÇÃO DOS ESTADOS AMERICANOS - OEA. Convenção Interamericana Para Prevenir, Punir e Erradicar A Violência Contra A Mulher. Belém do Pará,1994.

ORGANIZACIÓN DE LAS NACIONES UNIDAS PARA LA ALIMENTACIÓN Y LA AGRICULTURA - FAO. PANORAMA DE LA POBREZA RURAL EN AMÉRICA LATINA Y EL CARIBE: SOLUCIONES DEL SIGLO XXI PARA ACABAR CON LA POBREZA EM EL CAMPO. Santiago: Fao, 2018.

PIMENTEL, Silvia. Convenção para a Eliminação de Todas as Formas de Discriminação contra a Mulher: Apresentação. 20-?. Disponível em: http://www.onumulheres.org.br/wpcontent/uploads/2013/03/convencao_cedaw.pdf. Acesso em: 09 out. 2019.

ROUSSEFF, Dilma. Compromissos programáticos: Os 13 compromissos programáticos de Dilma Rousseff para debate na sociedade brasileira. 2010.

Disponível

em: http:/ / deputados.democratas.org.br/pdf/Compromissos_Programa ticos_Dilma_13\%20 Pontos_.pdf. Acesso em: 20 out. 2019.

ROUSSEFF, Dilma. Mais mudanças, mais futuro: Programa de Governo Dilma Rousseff. 2014. Disponível em: https://www.pt.org.br/wpcontent/uploads/2014/07/Prog-de-Governo-Dilma-2014-

INTERNET1.pdf. Acesso em: 20 out. 2019.

SÃO PAULO, Prefeitura de. Dia Nacional de Tereza de Benguela e da Mulher Negra. 2018. Disponível em: https:/ /www.prefeitura.sp.gov.br/cidade/secretarias/direitos_hu manos/igualdade_racial/noticias/?p=260988. Acesso em: 20 nov. 2019.

SILVA, Gabriela Galiza e. Comércio e Gênero: um novo tema na agenda internacional. Fgv Eesp - Textos Para Discussão: Working Paper Series. São Paulo, set. 2018. p. 1-60.

SILVA, Mariana Dionísio Cavalcante da. A equidade de gênero na agenda política do banco mundial. In: XXIX SIMPÓSIO DE 
HISTÓRIA NACIONAL, 24., 2017, Brasília. Anais do XXIX Simpósio Nacional de História - contra os preconceitos: história e democracia. São Paulo: Anpuh-sp, 2017. v. 1, p. 1 - 12.

UN WOMEN. Economic empowerment. 2013. Disponível em: https://www.unwomen.org/en/what-we-do/economicempowerment. Acesso em: 20 nov. 2019.

United Nations Development Programme - PNUD. Human Development Indicators: Brazil. 2018. Disponível em: http://hdr.undp.org/en/countries/profiles/BRA. Acesso em: 14 jun. 2019.

VIOTTI, Maria Luiza Ribeiro. Declaração e Plataforma de Ação da IV Conferência Mundial Sobre a Mulher: Apresentação. 2013. Disponível em: http://www.onumulheres.org.br/wpcontent/uploads/2013/03/declaracao_beijing.pdf. Acesso em: 10 out. 2019.

ZAEI, Mansour Esmaeil. Globalization of National Policy-Making: An International Perspective. Public Policy And Administration, Mykolas Romeris University [s.l.], v. 13, n 2, p. 331-340, 2014. 